\title{
Las Fuentes para la interpretación del Valle de Sébaco como subregión histórica.
}

Recepción: 12-08-2016/Aceptación: 08-11-2016

Sagrario Balladares N. sabanarro@yahoo.es

\section{Resumen}

El presente artículo ha sido elaborado con el propósito de compartir con los lectores una selección de fuentes para la interpretación de la Dinámica Social del valle de Sébaco como una sub región bistórica durante el periodo entre los siglos XVI y XIX. Para ello se emprendió una búsqueda de fuentes primarias, tales como las evidencias arqueológicas recuperadas en trabajos anteriores en la región, documentos históricos que se encuentran en los archivos parroquiales y archivos administrativos coloniales dentro y fuera del país, en este caso, en el Archivo General de Centroamérica nde Guatemala (AGCA), además, de los testimonios y descripciones dejadas por cronistas, visitas pastorales, viajeros; asi como algunas entrevistas de lideres y actores claves de las actuales comunidades indígenas de Sébaco y Matagalpa. También se han considerado otras fuentes secundarias, como las de tipo antropológicas, etnográficas, estadísticas, económicas, ecológicas, entre otras.

Se espera que los resultados del análisis de datos procedentes de estas fuentes sirvan para inferir desde una perspectiva bistórica, la dinámica social desarrollada en el valle de Sébaco durante el periodo propuesto.

Palabras Claves: Fuentes históricas, dinámica social, región histórica, valle de Sébaco, arqueología, antropologia, etnografía, ecología.

\section{Abstract:}

This paper has been written aimed at sharing with readers the social dynamic in the historical region of Sébaco Valley during XVI and XIX century; interpretation and selection of documental used. To achieve this a search of primary sources was carried out, such as archaeological evidence recovered in previous works at the valley, historical documents in parish archives, and colonial administrative files inside and outside the country, in this case The Central América General Archive, Guatemala (Archivo General de Centroamérica de Guatemala, AGCA); in addition to chronicles and interviews to leaders and key actors of indigenous communities in Sébaco and Matagalpa. It has also been considered other secondary sources such as anthropological, ethnographic, ecological and economic, among other.

Keywords: historical sources, social dynamic, historical region, Sébaco Valley, archeology, anthropology, ethnology, ecology. 


\section{INTRODUCCIÓN}

Este artículo se ha elaborado en el marco del Programa de Doctorado en Historia con énfasis en Estudios Regionales y Locales Transdisciplinarios, que se desarrolla desde el año 2015 el Departamento de Historia de la Facultad de Humanidades y Ciencias Jurídicas de la UNAN-MANAGUA. Es un requisito dentro del Seminario de Tesis II que contempla el programa académico.

Se refiere a la búsqueda y selección que se ha hecho de las fuentes para el estudio de del valle de Sébaco como una Sub región histórica muy dinámica social y económicamente e interrelacionada con muchos otros pueblos en el periodo comprendido entre los siglos XVI y comienzos del siglo XIX; que se inicia con la llegada de los europeos al territorio nacional, concluyendo justo en el momento en que se produce la independencia de Centroamérica.

A pesar de la existencia de datos del periodo colonial a través de los archivos parroquiales, documentos administrativos, crónicas, visitas pastorales y testimonios de viajeros en el país, éstos parecen no ser suficientes para alcanzar los objetivos propuestos con este estudio, ya que estas fuentes poseen mayormente información relacionada con la región del Pacífico nicaragüense, donde la administración colonial se asentó y se desarrolló prolíficamente quedando en ella presentes la mayoría de manifestaciones sociales y culturales ocurridas durante todo este periodo. Esto muestra un desequilibrio en cuanto a información se refiere, entre ésta y las otras regiones del país.

También se recurrirá a otros tipos de fuentes primarias como los documentos coloniales que se encuentran en el Archivo General de Centro América (AGCA) de la ciudad de Guatemala y con evidencias arqueológicas que fueron obtenidas en los últimos años como resultado de estudios desarrollados en algunos municipios de los departamentos de Matagalpa y Jinotega, área geográfica donde se inserta el objeto de estudio y parte de su hinterland.

Se han sido revisadas algunas fuentes primarias en el AGCA e informes técnicos inéditos sobre estudios arqueológicos recientes. La consulta de fuentes secundarias o bibliográficas, se ha realizado de dos maneras: a través del uso de herramientas digitales, localizando documentos, mapas, gráficos de carácter histórico en distintas páginas web en archivos y bibliotecas nacionales, regionales e internacionales; y la otra, realizando una búsqueda y revisión en físico en distintos centros de documentación; aunque a la fecha la búsqueda no ha concluido.

\section{Las fuentes y su acceso}

La revisión bibliográfica y documental para este estudio ha sido realizada a través de visitas a distintas páginas web especializadas en Historia $\mathrm{Na-}$ cional de Nicaragua, que se cuenta con archivos digitales que facilitan la consulta, permitiendo el acceso a documentos históricos, a publicaciones periódicas y de compilaciones históricas y arqueológicas relacionadas a nuestro territorio nacional, por ejemplo, todas las obras de la Colección Cultural del Banco Central de Nicaragua, pueden ser consultadas y descargadas de la web de la Biblioteca Virtual de la Fundación Enrique Bolaños con acceso libre y rápido. 
También se cuenta con la página web, memoriacentroamericana.ihnca.edu.ni del Instituto de Historia de Nicaragua y Centro América, INHCA, la cual contiene documentos importantes referidos a la historia social, económica y cultural de la región centroamericana. Ejemplo de ello lo conforman los documentos para la historia de Nicaragua en 17 tomos -extraída del Archivo General de Indias en Sevilla, España-, conocida también como la Colección Somoza, de la cual pueden obtenerse datos coloniales referidos al siglo XVI.

Esta misma web, cuenta con fondos bibliográficos del antiguo Instituto Histórico Centroamericano, el que contiene una biblioteca especializada en temas de Centroamérica que incluye algunos documentos del siglo XVIII, relativos al Descubrimiento, Conquista y Colonización del continente; entre ellas una recopilación de Leyes de Indias, la

58 Revista de la Academia de Geografía e Historia de Nicaragua y publicaciones periódicas oficiales, así como censos nacionales, cuya revisión puede generar datos de los siglos XV, XVI. Algunos de estos documentos contemplados también se encuentran en el AGCA.

Una página web de suma importancia es, www. archive.org de la biblioteca pública de New York, la cual contiene obras publicadas en el siglo XIX, sobre la historia general de América y sus raíces, América Central y sobre el Antiguo Reino de Guatemala, de interés para conocer el contexto en que fue iniciada la interpretación de nuestra historia nacional como tal.

Otras fuentes digitales, la conforman: la Revista de Historia también del INHCA, la Revista de temas nicaragüenses encontrada en http://www. temasnicas.net/revistas2014.htm., y que se edita desde mayo de 2008. Ambas proporcionan abundante información de diversos temas de Nicaragua y Centroamérica, en los distintos periodos históricos, reflexiones de eventos históricos concretos, descripciones etnográficas, testimonios, imágenes, documentos inéditos, y algunas veces presentan datos que se ubican fuera de la historia oficial.

También se encuentran digitalizadas, las constituciones políticas del país, y algunas de ellas en la siguiente dirección electrónica: http://nicaragua.justia.com/nacionales/ constituciones-politicas-de-nicaragua/, su revisión permitirá obtener datos jurídicos relacionados a transformaciones sociales y económicas como producto de las diversas divisiones políticas administrativas a lo largo del tiempo. Estos datos permitirán, conocer la dinámica geográfica o territorial de la subregión en estudio, la que muchas veces se manifiesta en detrimento de poblaciones indígenas aún presentes en el territorio nacional. Como complemento de lo anterior, también se cuenta con La Gaceta, diario oficial, para conocer datos sobre la expansión y contracción de la sub región objeto de estudio. Con la limitante que este diario oficial, se encuentra digitalizado a partir del año 2000 por lo que la visita a la Hemeroteca Nacional para la revisión física de las mismas es imperativa. Dicha revisión aportará datos para el estudio de periodos anteriores.

En el caso del acceso a las fuentes archivísticas, se tiene acceso al Archivo Nacional de Nicaragua, el que cuenta con información sistematizada y catalogada como: Descripciones de Cronistas y el Fondo de Gobernación, ambos fondos importantes para obtener datos sobre la población autócto- 
na o de descendencia indígena que aún pervive en la sub región de estudio.

También se ha tenido acceso al AGCA de la ciudad de Guatemala, para lo cual se requirió del aval de la Facultad de Humanidades y Ciencias Jurídicas y el cumplimiento estricto de las normas de permanencia y consulta de fuentes.

En cuanto a la consulta de fuentes gráficas pueden tratarse como referentes las distintas páginas web encontradas: http://www.mapahistorico. com/37/mapa-de-nicaragua.html; http://www. itme.org/mhni/refs \%20and\%20maps/Nicaragua-Atlas.pdf; http://mapasdecostarica.info/wp content/map/work/http.jpg/div0-0-0.jpg;

http:/ / www.mapahistorico.com/36/mapa-de-mexico.html

que ofrecen mapas históricos, desde las primeras cartas cartográficas relacionadas con las posiciones coloniales en el continente americano, incluyendo al antiguo reino de Guatemala y de la provincia de Nicaragua. También pueden encontrarse cartas cartográficas de la región del Caribe y de la actual Centroamérica de los siglos XVIII y XIX.

Por otra parte, se han retomado otras fuentes desde la perspectiva de los estudios regionales y locales, las cuales están referidas sobre todo a estudios latinoamericanos; utilizando la documentación proporcionada en los módulos cursados y herramientas digitales, seleccionando una serie de artículos especializados y científicos sobre aspectos teóricos-metodológicos.

Un ejemplo es el artículo titulado, "El espacio local y las inversiones extranjeras de fines de siglo" de las autoras, Silva B Grippo y Stella M.
Visciarelli, (2000), en el que realizan un análisis sincrónico del espacio, destacando los elementos significativos en el mismo para su reconstrucción histórica diacrónica, utilizando el concepto espacio proporcionado por la geografía histórica.

El artículo titulado, "El puerto como espacio de debate en la discusión interdisciplinaria", de los autores, Adriana C. Rodríguez, Sandra Tonelloto y Roberto Bustos Cara, (2000), enfocado al rescate de elementos resultantes de una dinámica social en un espacio concreto a lo largo de un periodo tiempo determinado, dejando entrever la ampliación y disminución de los límites de ese espacio estudiado, es decir, la aplicación de este concepto de puerto, permitió conocer la evolución propia de la localidad así como su hinterland y territorios conexos, ya que fue aplicado desde el enfoque de la microhistoria.

América Central como región geográfica de Carolyn Hill (1985), es otro de los artículos que muestra una síntesis desde una perspectiva biofísica de la región centroamericana, interesante para comprender posibles accesos y rutas de intercambio posibles desde la antigüedad. El análisis de éstos y otros artículos ayudará al conocimiento de la evolución de la subregión histórica del Valle de Sébaco.

El valle como tal, ha sido estudiado desde diversas disciplinas, produciéndose una bibliografía que proporciona muchos elementos significativos desarrollados en esta área, tanto de carácter fisiográfico como social e histórico. Se mencionan entre otros, el Inventario de Sitios Arqueológicos en los departamentos de Matagalpa y Jinotega (Balladares y Rivera, 2006 y Balladares y Lechado, 2010), el que contiene datos de ocupaciones antiguas en 
el territorio; la Geografía Dinámica de Nicaragua del Dr. J. Incer (2000), refiriéndose a la formación del relieve nicaragüense y destacando a este valle junto a otros dentro de la topografía nacional.

Desde las ciencia del agua por su potencial acuífero, ha sido tratado por el Centro de Investigación para los Recursos Acuáticos, CIRA de la UNAN, Managua en diversos temas relacionados a este campo. Por ejemplo, en el 2010 se realizó estudio de los Acuíferos y su cuenca de captación aluvial, formulándose el plan de gestión de dicha cuenca, estudios de calidad y disponibilidad del recurso hídrico (2013).

El instituto de Estudios Territoriales, INETER, también ha desarrollado estudios hidroquímicos de los acuíferos (1989), isotópicos del acuífero aluvial (1985); por su potencial agrícola, el Ministerio Agropecuario y Forestal MAG-FOR (2008), y dentro del marco para el desarrollo del Plan Nacional de Desarrollo Humano, realizó un estudio en el que incluye al valle de Sébaco para la formulación del sub programa nacional de frutas y hortalizas y muchos otros, respondiendo a necesidades nacionales de carácter económico.

Lo anterior demuestra que la mayoría de estudios técnicos-científicos desarrollados en el valle están dirigidos a los recursos que posee, a su preservación, disponibilidad, explotación y calidad de los mismos, lo que permitirá inferir sobre las posibles actividades económicas que han sido desarrolladas a lo largo del tiempo. También existe bibliografía de estudios municipales actualizados (Ciudad Darío, San Isidro y Sébaco) sobre la caracterización de los mismos enfocados igualmente, a los recursos que cada municipio posee.

\section{La historia nacional y las fuentes}

La revisión bibliográfica realizada hasta la fecha sobre la historia nacional, demuestra que ha sido la región del Pacífico nicaragüense la más estudiada; de manera breve la región Centro-Norte y casi nula para la región del Caribe. Para todas ellas en general el discurso explicativo de que la historia oficial se inicia con la llegada de los europeos: los ingleses en el Caribe y los españoles en el resto del país. Además, se suelen introducir breves síntesis retrospectivas sobre los grupos que se encontraban asentados en el actual territorio nacional al momento de la llegada de los europeos, las que se han realizado a partir de las descripciones hechas por los cronistas.

Los historiadores que interpretaron y realizaron la historia nacional desde sus inicios en el siglo XIX, basaron su narrativa en las crónicas escritas por Oviedo y Valdés, Fray Bartolomé de las Casas, Don Antonio de Herrera; sobre historia general de América, América Central y del Antiguo Reino de Guatemala, escritas por, Abate Brasseur de Bourbowg (1857 y 1859), Mr, Hubert Howe Bancroft (1886), Diego Barros Arana (1865); Domingo Juarros y García Peláez (1851); y obras como las de E.G. Squier (1852) y Paul Levy (1873).

Por tanto, la interpretación de nuestra historia nacional parece ser que se inicia con la colonización europea en el continente americano, dejando por fuera los procesos socio - evolutivos desarrollados sin duda desde la llegada de sus primeros pobladores en tiempos pretéritos.

Así por ejemplo, Don José Dolores Gámez, (1975:14) historiador clásico nicaragüense, subdividió en tres grandes periodos la historia nacional: historia antigua o aborigen, historia colonial 
o dominación española e historia moderna o independiente; esta última subdividida en: Etapa Imperio de México (1821-1823), Etapa de la República Federal Centro Americana (1823-1838) y Etapa de la República (a partir de 1838). Resultando ser ésta la primera propuesta de periodización histórica para Nicaragua surgida finales del siglo XIX.

Esta división refleja claramente el sesgo en la interpretación de la historia debido a la exclusión de la región caribeña, la que también es parte del territorio nacional; quizá se debió a que en aquél momento aún no se consolidaba el Estado Nacional nicaragüense, ya que se mantenía fuertemente la influencia inglesa en esa región a pesar de la suscripción del Tratado de Managua de 1860 entre Inglaterra y Nicaragua, a través del cual el primero reconocía el derecho del segundo sobre todo el territorio.

Otro elemento importante fue que en el último cuarto del siglo XIX, como consecuencia del proceso de consolidación del Estado Nacional, hubo una iniciativa oficial de elaborar la historia nacional para que fuese impartida en todos las escuelas públicas del país. Dentro de este contexto la interpretación de la historia como Nación, fue explicada, por este mismo autor, a partir de los procesos migratorios procedentes del norte de la región centroamericana ocurridas entre el 800 y el 1200 d.C., procesos que han sido denominados como migraciones mesoamericanas basado en datos obtenidos de las crónicas, a pesar de haber concebido el periodo antiguo o aborigen desde el origen de la sociedad centroamericana. Se requiere ahondar en el concepto de sociedad para un mejor entendimiento.
Por otra parte, Don Tomás Ayón (1977: 41-47), historiador de ideas colonialistas en su obra titulada, Historia de Nicaragua desde los tiempos remotos hasta el año de 1852, publicada en tres tomos por primera vez en 1956, inicia su narrativa destacando características y aportes de las grandes sociedades aborígenes del continente americano, y haciendo énfasis en la sub región cultural llamada Mesoamérica, hasta particularizar con las sociedades que se encontraban asentadas en el actual territorio nacional a la llegada de los españoles. Su visión de la historia no aportó ningún cambio sustancial con relación a la interpretación realizada por J.D. Gámez, marcando ambos, la pauta para el inicio del discurso histórico nacional de Nicaragua, pues a partir de entonces la mayoría de las interpretaciones sobre la historia nacional han sido bastante comunes en escala temporal. En consecuencia, se mencionan historiadores como, Lola Soriano con su Monografía de Matagalpa (1967), Jaime Incer Barquero con su obra titulada, Descubrimiento, conquista y exploración de Nicaragua (2002) y Jorge Eduardo Arellano en su Nueva Historia de Nicaragua (1990) e Historia Básica de Nicaragua (1993).

En este sentido, casi toda la literatura histórica del país comienza su narración refiriéndose a las descripciones hechas por los cronistas sobre la llegada de los grupos mesoamericanos, sus influencias y transculturación para con los grupos aborígenes autóctonos de Nicaragua, resaltando la herencia o legado de los primeros. Es decir, la historia de Nicaragua se inicia con la interpretación plasmada en las crónicas producto de la visión europea, por tanto, se reafirma que la interpretación de nuestra historia nacional parte con la llegada de éstos, dejando por fuera milenios de historia construida por los aborígenes en estas tierras. 
Así por ejemplo, cuando se refieren a la historia antigua, el discurso histórico en general presenta un gran vacío temporal que hasta el día de hoy no ha sido superado. En este sentido solamente se hace referencia a las improntas o huellas de Acahualinca, con más de cinco mil años de antigüedad, las que quedaron plasmadas a la orilla del lago Xolotlán, al noroeste de la actual ciudad capital; y al sitio Angie, un conchero registrado en la localidad de Monkey Point en el Caribe nicaragüense. Ambos sitios se mencionan dentro del discurso como las evidencias más antiguas de Nicaragua, e inmediatamente se aborda a las sociedades aborígenes que se encontraban asentadas en el territorio nacional a la llegada de los conquistadores en el siglo XVI, quedando así un gran vacío histórico y temporal.

Sin duda se debe al poco desarrollo que ha te62 nido la arqueología nacional y además a que las crónicas de indias, los archivos parroquiales y los archivos creados durante la administración colonial, son las únicas fuentes primarias escritas con las que se cuentan para la interpretación de la historia nacional. Hasta este momento han sido esporádicas las iniciativas gubernamentales por la recopilación de documentos que se encuentran dispersos en distintos archivos del mundo y que están relacionados con nuestra historia. Urge en la actualidad, la conformación del archivo histórico nacional donde se concentre toda la información arqueológica e histórica de Nicaragua.

En cambio para el abordaje del periodo colonial, las fuentes documentales han permitido a los historiadores nacionales construir discursos sobre muchos eventos de carácter social, políticos, económicos, religiosos y culturales, ocurridos durante este periodo, los que han quedado marcados en la memoria colectiva, tal es el caso de las medidas administrativas coloniales implementadas a las poblaciones aborígenes, manteniéndose este enfoque mayormente sobre la región del Pacífico donde se instaló la administración político-administrativa-religiosa colonial, irradiándose esta interpretación para al resto de los poblados y/o corregimientos creados dentro de la provincia de Nicaragua.

Los resultados de este enfoque histórico se han generalizado para el resto de sociedades o grupos que se encontraban en la región Centro-Norte del actual territorio nacional, obviando las particularidades que estas sociedades pudiesen haber tenido en comparación con las de la región del Pacífico. Cabe resaltar que los españoles arribaron un poco más tarde al Centro-Norte del país, donde los grupos que ahí se encontraban indudablemente no funcionaron ni se desarrollaron de igual manera que los que se encontraban en el Pacífico, ya que poseían sus propias peculiaridades, siendo por ejemplo, la lengua su principal diferencia, las actividades económicas marcadas por los tipos de cultivos y los recursos que cada una poseía.

\section{Fuentes para el estudio del Valle de Sébaco como sub región histórica}

Para el estudio de esta sub región histórica en los siglos XVI al XIX, encontramos las mismas fuentes archivísticas, documentales y bibliográficas que ya han sido referidas ut supra, tanto dentro como fuera del país.

Para una aproximación al conocimiento del comportamiento histórico social de la sub región del valle de Sébaco, se requiere consultar detenidamente los archivos parroquiales de la ciudad de 
Granada. León y Matagalpa, de los cuales pueden extraerse datos sobre dinámicas diversas de la población indígena, por ejemplo, datos de productos de las cofradías, censos poblacionales, de movilidad de indígenas, indígenas cristianizados en los corregimientos de Sébaco y Chontales, y más tarde del corregimiento de Matagalpa; así mismo de los Partidos de León y Segovia.

Esta información pueden ser comparados con los que contiene la obra titulada, "La población del Nicaragua, 1748-1867, de Mercedes Mauleón Isla (2008), misionera mercedaria e historiadora, la cual abunda en datos estadísticos significativos de estos siglos y cuyo análisis permitirá conocer algunas conexiones, movimientos poblacionales, densidad de población, actividades económicas; que constituyen indicadores sustanciales para el conocimiento de la dinámica poblacional en la subregión tal como el aumento y descenso de población, ejemplo de ello, la despoblación de la que da cuenta Fray Margil de Jesús a comienzos del S.XVIII, ocurrida en el valle de Sébaco con la llegada de los españoles a la zona, y por otra parte, la resistencia de los indígenas ante este fenómeno. Probablemente este análisis arrojará algunos datos importantes que involucran al Norte Centro del país. Se procurará además, el acceso a los archivos de las comunidades indígenas actuales de Sébaco y Matagalpa

Ahora bien, las obras de autores como Jerónimo Pérez (1928) y Francisco Ortega Arancibia (1957), a pesar que ambos abordaron el periodo post independentista, aportan datos de algunas manifestaciones concretas cuyo origen se encuentran dentro de los procesos históricos que se iniciaron en el siglo XVIII. Jerónimo Pérez trató sobre hechos ocurridos en el siglo XIX, enfocán- dose en eventos particulares de la evolución social, las que se plasman en sus memorias publicadas parcialmente desde 1865, y compiladas en la obra titulada, Memorias para la Historia de la Revolución de Nicaragua en 1854, editada en 1928 y Ortega Arancibia, con su obra, Cuarenta años (1838-1878) de Historia de Nicaragua, publicada su segunda edición en 1957.

También la obra Monumenta Centroamericae Historica (1965) de Don Federico Arguello Solórzano y Don Carlos Molina Arguello, es una buena fuente de las leyes, administración, funcionamiento y oficios de los siglos XVI y XVII, ya que contiene una colección de documentos y materiales extraídos del Archivo General de Indias AGI de Sevilla, España para el estudio de los pueblos de la América Central tal como lo especifica en su portada. Se encuentra digitalizado en la web del IHNCA, memoriacentroamericana.ihnca.edu.ni

El estudio sobre las estructuras sociales de Nicaragua en el S XVIII, del Dr. Germán Romero Vargas (1987), ha sido una de las obras más completas sobre las relaciones que se desarrollaron dentro de la sociedad colonial, fundamentalmente para las sociedades asentadas en la región pacífica de Nicaragua. A pesar de tocar parcialmente al actual territorio nacional, esta obra ha dado algunos destellos para la búsqueda de dinámicas sociales en las otras regiones del país, en este caso, ha servido de mucho para dirigir las consultas bibliográficas relacionadas con la región Centro-Norte con énfasis en el valle de Sébaco y su hinterland.

Finalmente, se cuenta con algunos testimonios y entrevistas de algunos descendientes de las comunidades indígenas de Sébaco, Matagalpa y Muy Muy. 


\section{Conclusiones}

Desde el siglo XIX los investigadores se han venido refiriendo al problema de las fuentes históricas para Nicaragua, ya que el país no cuenta con su propio acervo, un ejemplo fue Don Tomás Ayón.

La mayoría de fuentes históricas documentales y bibliográficas disponibles en Nicaragua, sobre todo para el estudio de los siglos XVI y XIX, se enfocan en mayor número a la región del Pacífico como consecuencia del desarrollo de diversas dinámicas durante el periodo colonial, ya que en ella se encontraban los principales centros administrativos coloniales: Granada y León. Esto permitió que la producción de archivos administrativos y de orden jurídico se generara principalmente en estas ciudades, así como también los archivos parroquiales, con la particularidad que estos últimos se generaron también en Matagalpa.

Esta revisión de las fuentes ha permitido detectar que el principal problema es la falta de compilación y centralización de las mismas dentro del país (a pesar de que se han realizado esfuerzos por hacer compilaciones de fuentes primarias que se encuentran fuera del país).

Para solucionarlo se requiere dar continuidad a las acciones como las que produjeron la Colección Somoza, la cual consta de documentos coloniales que se encuentran en el Archivo General de Indias en Sevilla, España, donde existen, según Manuel Ignacio Pérez Alonso, historiador jesuita, documentos relacionados a Nicaragua desde la llega de los europeos hasta la independencia. Este esfuerzo digno de reconocimiento de parte de la academia, pero no es suficiente para contar con todo el acervo histórico de Nicaragua.
Lo anterior indica que se tiene una ardua tarea por delante para la recuperación de documentos históricos que se encuentran dispersos en distintos archivos del mundo. Como sugerencia es la creación del Archivo Histórico de la Nación, o bien, un fondo documental del periodo colonial dentro del actual Archivo Nacional. Esta tarea es alcanzable comenzando con la obtención de una copia del Fondo Documental que posee el Archivo General de Centro América de Guatemala (AGCA), urgente tarea ya que en la actualidad el fondo que ahí se alberga se encuentra en un estado de conservación lamentable. Esta puede ser una de las funciones de nuestras embajadas del mundo.

\section{Referencias bibliográficas}

Arellano, Jorge E. (1990). Nueva historia de Nicaragua. Volumen 1. Fondo Editorial CIRA. . (1993). Historia Básica de Nicaragua. Volumen II. Fondo Editorial CIRA. Ayón, Tomás. (1977). Historia de Nicaragua. Tomo I y II. Colección cultural del Banco de América. Serie Histórica 10 y 11.

Balladares, Sagrario y Rivera, Flor Ma. (Inédito 2006). Inventario de Sitios Arqueológicos en los departamentos de Matagalpa y Jinotega. CADI. UNAN-Managua.

Balladares, Sagrario y Lechado, Leonardo. 2010. El inventario de sitios arqueológicos en Nicaragua. Una metodología participativa. Recuperado en http://www.hcentroamerica.fcs. ucr.ac.cr/Contenidos/hca/cong/mesas/x_ congreso/arq-patrimonio/inv-arqueologia. pdf

Chirino Ramos, María de los Ángeles (2004). Los archivos de Nicaragua: problemática y situación actual. Instituto de Historia de Nicaragua 
y Centroamérica. IHNCA. Pág. 1. Recuperado en http://bid.ub.edu/12chiri2.htm

Flores Meza, Yelba. 2004. Criterios hidrogeológicos para formulación del plan de gestión en el acuífero del valle de Sébaco. (Tesis de Maestría). CIRA-UNAN-Managua. Recuperado en http://www.cira-unan.edu.ni/media/documentos/YFlores.pdf

Gámez, José Dolores (1975). Historia de Nicaragua. Fondo de Promoción Cultural Banco de América. Serie histórica No. 3.

(1975). Historia Moderna

de Nicaragua. Complemento a mi historia de Nicaragua. Fondo de Promoción Cultural del Banco de América.

Grippo, Silvia G. y Visciarelli, Stella M. (2000). "El espacio local y las inversiones extranjeras a fines de siglo", en Bustos Cara, Roberto y Cernadas de Bulnes, Mabel N. (eds.): Estudios regionales interdisciplinarios II, Universidad Nacional del Sur, Bahía Blanca, Argentina, pp. 199-211.

Hall, Carolyn. (1985). América Central como Región Geográfica. Anuario de Estudios Centroamericanos, Universidad de Costa Rica, 11 (2): 5-24.

INETER. Mapa fisiográfico de Nicaragua. 2000. http://www.zonu.com/mapas_nicaragua/ Mapa_Fisico_Geografico_Nicaragua.htm

MAG-FOR (2008). Sub programa nacional de frutas y hortalizas. Guillermo Castillo C, Tomás Laguna y Jorge Alfaro T. Recuperado en www.magfor.gob.ni/prorural/.../perfilessub/ frutasyhortalizas.pdf

Ortega Arancibia, Francisco.1974. Cuarenta años (1838-1878) de Historia de Nicaragua. Colec- ción Cultural Banco de América. Serie histórica No. 6.

Pérez Alonso, Manuel Ignacio (1980). "Relación de documentos relativos a Nicaragua,

existentes en archivos y bibliotecas del extranjero". Boletín del Archivo General de la $\mathrm{Na}$ ción, no 4-5 (1980), p. 39-48.

Pérez, Jerónimo. (1975). Obras histórica completas. Colección Cultural Banco de América. Serie histórica No. 5.

Pérez Estrada, Francisco. 1982. Panorama de la Nicaragua Pre-colonial, Ministerio de Educación. Nicaragua.

Rodríguez, Adriana C., Tonelloto, Sandra y Bustos, Roberto. 2000. "El puerto como espacio de debate en la investigación interdisciplinaria”, en Bustos Cara, Roberto y Cernadas de Bulnes, Mabel N. (eds.): Estudios regionales interdisciplinarios II, Universidad Nacional del Sur, Bahía Blanca, Argentina, pp. 105-121

Romero Vargas, German. et. al. 1987. Las estructuras sociales de Nicaragua en el siglo XVIII. Editorial Vanguardia. Managua.

Soriano de Guerrero, Lola. (1967). Matagalpa. Monografía. $\mathrm{N}^{\circ}$ 8. Colección Nicaragua, Guerrero Castillo.

\section{Siglas}

AGCA: Archivo General de Centroamérica. Ciudad Guatemala.

AGHN: Academia de Geografía e Historia de Nicaragua.

AGI: Archivo General de Indias en Sevilla. España.

INH-CA: Instituto de Historia de Nicaragua y Centro América. 